\title{
AÇIK MADEN SAHA SINIRLARININ PIKKSEL TABANLI VE NESNE TABANLI SINIFLANDIRMA TEKNIKLERİ İLE ÇIKARIMI
}

\author{
Abdullah Harun INCEKARA ${ }^{1}$, Ahmet DELEN ${ }^{1}$, Tolga BAKIRMAN², Bülent BAYRAM ${ }^{3}$, Dursun \\ Zafer ŞEKER ${ }^{4}$
}

${ }^{1}$ Arş. Gör., Gaziosmanpaşa Üniversitesi, Mühendislik ve Doğa Bilimleri Fakültesi, Harita Mühendisliği Bölümü, 60150, Taşlıçiftlik, Tokat, (abdullah.incekara;ahmet.delen)@gop.edu.tr

${ }^{2}$ Arș. Gör., Yıldız Teknik Üniversitesi, İnşaat Fakültesi, Harita Mühendisliği Bölümü, 34220, Esenler, İstanbul, bakirman @yildiz.edu.tr

${ }^{3}$ Prof. Dr., Yıldız Teknik Üniversitesi, İnşaat Fakültesi, Harita Mühendisliği Bölümü, 34220, Esenler, İstanbul, bayram@yildiz.edu.tr

${ }^{4}$ Prof. Dr., İstanbul Teknik Üniversitesi, İnșaat Fakültesi, Geomatik Mühendisliği Bölümü, 34469, Maslak, İstanbul, seker@itu.edu.tr

\section{ÖZET}

Taş ocakları yeryüzü üzerinde açık maden sahaları olarak işletilen doğal kaynaklardandır. Mevcut kaynakların etkin ve sürdürülebilir kullanımı hem ekonomiye katkı hem de çevreye olan etkileri dolayısıyla önemlidir. Bu nedenle açık maden sahalarında yasal olarak belirlenmiş ruhsat sinırları içerisinde yürütülmekte olan faaliyetlerin zamansal olarak takibinin yapılması gerekmektedir. Maden sahasını çevreleyen dış sınırdaki değişiklikler bu konu hakkında bilgi verici niteliğinde olup görüntü verileri üzerinde uygulanan çeşitli sınıflandırma teknikleri ve algoritmaları yardımıyla elde edilebilmektedir. Bu çalışmada Antalya ili Elmalı ilçesinde yer alan ormanlık bölgede işletilmekte olan açık maden sahası çalışma alanı olarak belirlenmiştir. Madene ait işletme sinırı 6 m mekânsal çözünürlüklü Spot 6 uydu görüntüsü kullanılarak elde edilmiştir. Maden sınırını elde edebilmek için piksel tabanlı ve nesne tabanlı sınıflandırma teknikleri uygulanmıștır. Piksel tabanlı sınıflandırma En Büyük Benzerlik algoritması kullanılarak uygulanmıştır. Nesne tabanlı sınıflandırma ise NDVI ile oluşturulan kurala dayalı olarak gerçekleştirilmişstir. Sinıflandırılmış görüntüler üzerinden çıkarılan maden sınırına ait vektörler $4 \mathrm{~cm}$ yer örneklem aralığına sahip ortofoto üzerinden sayısallaştırma ile elde edilen referans sınır ile karşılaş̧tırılmıştır. Çıkarılan ve sonrasında yumuşatma işlemi uygulanan sinırlar üzerinde $6 \mathrm{~m}$ aralıklar ile noktalar üretilmiștir. Üretilen noktalar ile referans sinır arasında en kısa mesafe uzaklıkları belirlenmiştir. Elde edilen mesafelerin ortalamaları piksel tabanlı ve nesne tabanlı sınıflandırma için sırasıyla $2.25 \mathrm{~m}$ ve 1.19 m olarak hesaplanmıştır. Her iki sınıflandırma tekniğinde de yarım piksel boyutundan daha düşük sonuçlar elde edilmiştir.

Anahtar Sözcükler: açık maden ocağı, nesne tabanlı sınıflandırma, orman, piksel tabanlı sınıflandırma

\section{ABSTRACT \\ EXTRACTION OF OPEN MINING BOUNDARIES BY UTILIZING PIXEL-BASED AND OBJECT-BASED CLASSIFICATION TECHNIQUES}

\begin{abstract}
Quarries are natural resources operated as open mine area on the earth surface. Effective and sustainable use of available resources is essential both for the contribution to the economy and for the environment. For this reason, it is necessary to perform the temporal follow up of the activities that are carried out within the limits of licences which are legally determined in the open minefields. The changes in the outer boundary surrounding the mining area are informative about this topic and can be obtained by means of various classification techniques and algorithms applied on the image data. In this study, an open minefield operated in a forest region in Elmall district of Antalya province was selected as study area. The operation boundary of the mine was obtained by means of Spot 6 satellite image with the spatial resolution of $6 \mathrm{~m}$. Pixel-based and object-based classification techniques were applied to obtain mine boundary. Pixel-based classification was implemented by using the Maximum Likelihood algorithm. Object-based classification was performed based on the rule generated by NDVI. Vectors belonging to the mine boundary extracted from classified images were compared with the reference boundary obtained by manual digitization over orthophoto with a ground sampling distance of $4 \mathrm{~cm}$. Points at intervals of $6 \mathrm{~m}$ were produced on the boundaries where smoothing was applied after extraction. The nearest distances between the points produced and digitized boundary were determined. The averages of the obtained distances were calculated as $2.25 \mathrm{~m}$ and $1.19 \mathrm{~m}$ for the pixel-based and object-based classification, respectively. Both techniques yielded values lower than half a pixel size.
\end{abstract}

Keywords: open mine area, object-based classification, forest, pixel-based classification

\section{GİRIŞ}

Ülkelerin enerjiden sonraki temel gereksinim maddeleri endüstriyel kayaçlar ve minerallerdir. Türkiye yer altı ve yer üstü kaynakları bakımından zengin bir ülkedir ve yer üstü kaynaklarını oluşturan kayaçların taş ocakları işletmeleri ile çıkartılması ülke ekonomisi için önem arz etmektedir. Açı maden sahalarında çıkarılan mermer, çakıl vb. ham maddeler bu kategoriye girmektedir. Taş ocaklarında çıkarılan ham maddelerden farklı sektörlerde yararlanılmaktadır ve 2016 yılı itibarıyla Türkiye'de madencilik sektörünün gayrisafi millî hasıladaki payı \%0.82 iken 2016'dan 2017'ye ihracat \%23.74 oranında artmıştır. Ülkemizde madencilik faaliyetleri için arama ve işletme olarak 2 adet ruhsat verilmektedir. Mevcut durumda yaklaşık olarak 11000 adet açık maden sahasının işletme ruhsatı bulunmaktadır (URL-1). Kazı çalışmalarının ilerlemesi, çıkarılan ham maddelerin biriktirilmesi ve taşınması açık maden sahasını çevreleyen dış sınırın zaman içerisinde değişmesine neden olmaktadır. Bununla birlikte madencilik faaliyetlerinin 
gerçekleştirildiği maden ocağı için çalışma sınırları işletme ruhsatı ile belirlenmiştir. Dolayısı ile mevcut çalışma sınırlarındaki değişikliklerin tespiti için açık maden sahalarında zamansal takip yapılması gerekmektedir (Paul vd., 2006; Erener, 2011). Bu amaçla arazide geleneksel yöntemler ile gerçekleştirilecek ölçmeler geniş ve çoğu zaman tehlikeli ve eğimli bir alana yayılan taş ocakları için zaman ve maliyet açısından dezavantajlı olabilmektedir.

$\mathrm{Bu}$ çalışmada ormanlık alanda işletilmekte olan bir taş ocağını çevreleyen sınır piksel tabanlı ve nesne tabanlı sınıflandırma teknikleri ile belirlenmiştir. Maden ocağının konumu dolayısıyla işletme sınırlarının genişlemesi ormanlık alanda azalmayı beraberinde getirmektedir. Dolayısıyla bu tür maden sahalarının ekonomik açıdan önemi göz ardı edilmeden çevresel duyarlılığı da dikkate alarak izlenmesi gerekmektedir. Piksel tabanlı sınıflandırma örnek alanlara bağlı olarak gerçekleştirilmiştir. Nesne tabanlı sınıflandırma ise belirgin bir şekilde farklı spektral yansıma özelliklerine sahip nesnelerin varlığı nedeniyle daha yüksek doğruluk elde edileceği düşünülerek kurala dayalı olarak gerçekleştirilmiştir. Vektör formatında çıkarılan maden sınırları çalışma alanına ait ortofoto üzerinden sayısallaştırma ile elde edilen referans sınır ile karşılaştırılmıştır. Ortofoto üretimi için kullanılan fotoğraflar İnsansız Hava Aracı (İHA) ile elde edilmiştir. Bu çalışmada, İHA'dan elde edilen veri ile uydu görüntüsünün sınıflandırılması ile elde edilen veriler doğruluk açısından birbirleriyle karşılaştırılmamaktadır. Sınıflandırma teknikleri ile doğru olduğu kabul edilen referans veriye ne kadar yaklaşılabildiği test edilmektedir. Bu amaçla uydu görüntüsü üzerinden çıkarılan sınırlar ile referans sınır arasında minimum mesafe değerleri yakınlık analizi kapsamında hesaplanmıştır. Bu değerler üzerinden ise istatistik sonuçlar elde edilmiştir.

\section{VERİ VE YÖNTEM}

Çalışma alanı ve kullanılan görüntü verileri Şekil 1'de yer almaktadır. Çalışma alanı olarak belirlenen maden sahasının çevresinde başka açı maden ocakları da mevcuttur. Sınıflandırma aşamasında kullanılan veri 26.07.2017 tarihli $6 \mathrm{~m}$ mekânsal çözünürlüğe sahip multispektral Spot 6 uydu görüntüsüdür. Görüntü 3A seviyesinde ortorektifiye olarak temin edilmiştir ve RGB ile NIR bantlarına sahiptir. Sayısallaştırma için kullanılan veri ise İHA ile elde edilen fotoğraflar yardımıyla üretilen ve $4 \mathrm{~cm}$ piksel boyutuna sahip ortofotodur. Bölgenin 2009, 2011, 2014 ve 2017 yıllarındaki değişimi ise Şekil 2'de gösterilmektedir.

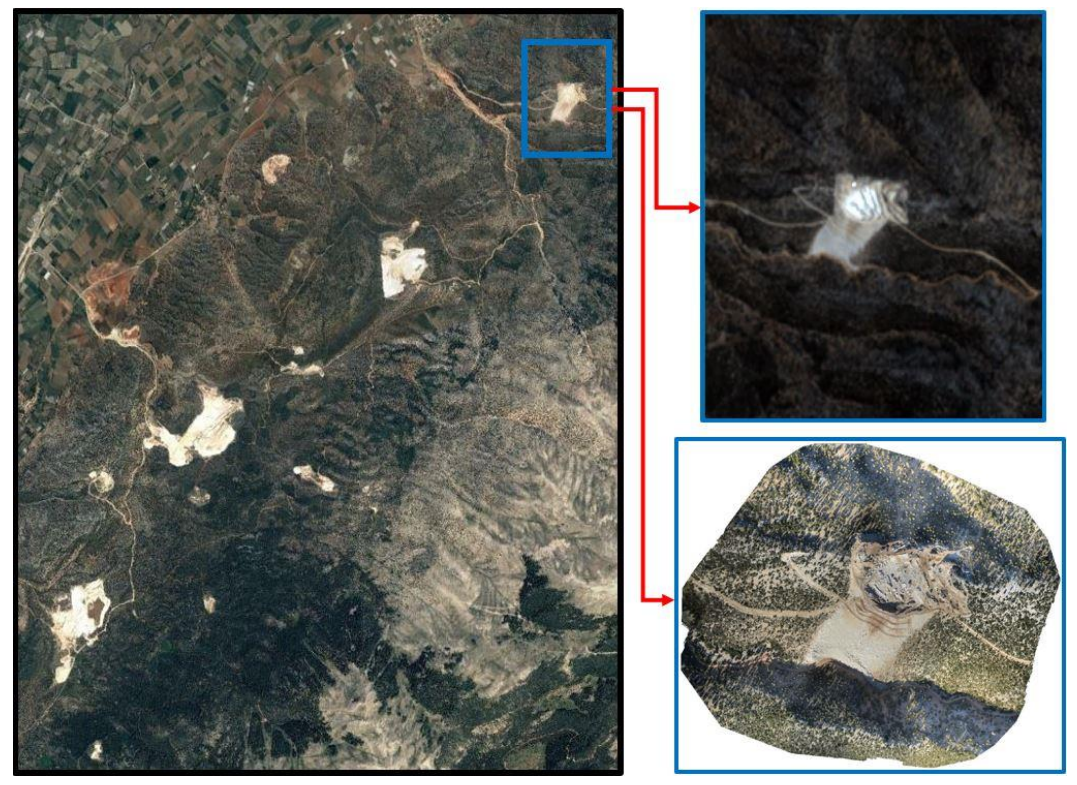

Şekil 1. Çalışma alanı.
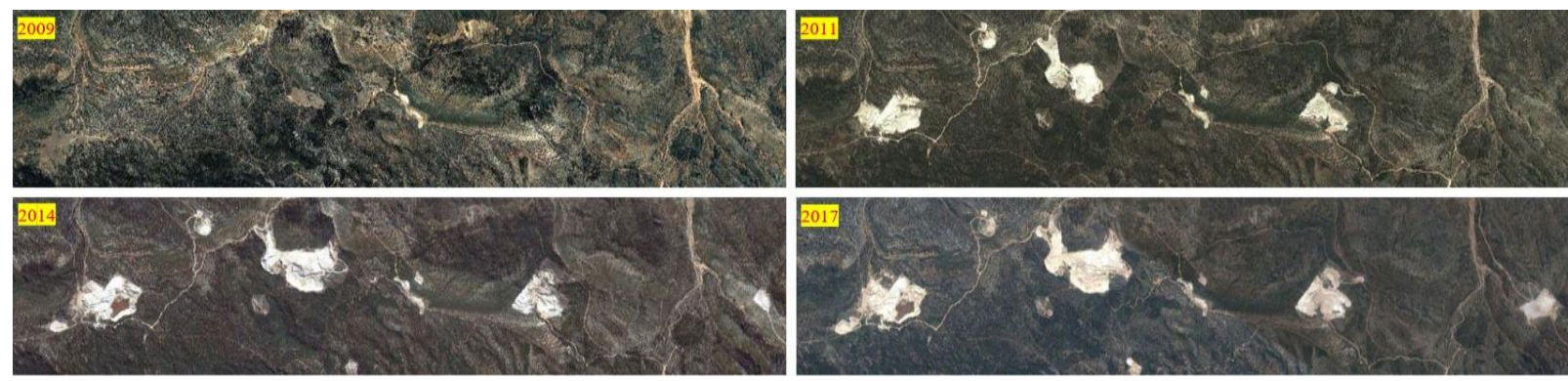

Şekil 2. 2009-2017 yılları arası değişim. 
Piksel tabanlı sınıflandırmada En Büyük Benzerlik (EBB) algoritması kullanılmıştır. Sınıflandırma öncesinde Maden1, Maden-2, Sık Orman, Seyrek Orman-1, Seyrek Orman-2 ve Yol olarak 6 adet sınıf belirlenmiştir. Maden sınırları içerisinde kazı yapılmış ve yapılmamış bölgeler farklı spektral yansıma karakteristiklerine sahip olduklarından dolayı 2 sınıf altında örnek alanlar tanımlanmıştır. Sınıflandırma sonrası ise Maden adında tek sınıf altında birleştirilmişlerdir. Benzer işlem seyrek orman için de uygulanmıştır. Ormanlık alanın seyrekleştiği yerlerdeki yoğunluklar farklı olduğundan dolayı 2 sınıf altında örnek alanlar tanımlanmış ve sınıflandırma sonrası Seyrek Orman adında tek sınıf altında birleştirilmişlerdir. Maden sahasına ulaşımı sağlayan yol bazı bölgelerde maden sahası bazı bölgelerde ise seyrek orman ile benzerlik göstermektedir. Yol sınıfı için tanımlanan örnekler ile oluşturulan sınıfta daha sonrasında Seyrek Orman sınıfına dahil edilmiştir. Sonuç olarak 6 adet spektral sınıf ile piksel tabanlı sınıflandırma işlemi EBB algoritması kullanılarak gerçekleştirilmiştir ve sonrasında sınıf sayısı birleştirme işlemi ile 3'e indirilmiştir.

Nesne tabanlı sınıflandırmanın ilk aşamasında benzer spektral özelliklere sahip pikselleri bir araya getirerek görüntü nesnelerini oluşturmak amacıyla çoklu çözünürlük bölütleme işlemi uygulanmıştır. Bu aşamada ölçek, şekil ve yoğunluk değerleri görsel yorumlama ve deneme-yanılma ile sırasıyla $25,0.1$ ve 0.5 olarak belirlenmiştir. Çalışma alanının ve hedef objenin kapsamı nedeniyle belirgin bir etkisi olmayacağından dolayı (Kavzoğlu ve Yıldız, 2014) yoğunluk değeri değiştirilmemiştir. Uygulanan ölçek parametresi sonrasında lineer özelliğe sahip maden sahasının dış sınırını daha iyi elde edebilmek için şekil değerinin arttırılmasına da gerek kalmamıştır. Hedef bölge sadece maden sahası olduğu için diğer bölgelerdeki görüntü nesneleri yorumlama ve değerlendirme sırasında dikkate alınmamıştır. Görüntü nesneleri üzerinde NDVI değerlerine dayalı olarak uygulanan kural ile maden sahası, çevresindeki ormanlık alandan ayrılmıştır. NDVI değerleri maden sahası için 0 ile 0.1 arasındadır. Ormanlık bölge için ise NDVI değerleri çoğunlukla 0.2 'den büyüktür. 0.1 'den küçük NDVI değerine sahip görüntü nesneleri Maden sinıfına atanarak nesne tabanlı sınıflandırma tamamlanmıştır. Maden sahasına ait görüntü nesneleri ve NDVI görüntülerine ait görseller Şekil 3 'te yer almaktadır. Her iki teknikle sınıflandırılmış madenin uydu görüntüsü üzerinde gösterimi ise Şekil 4'te sunulmaktadir.

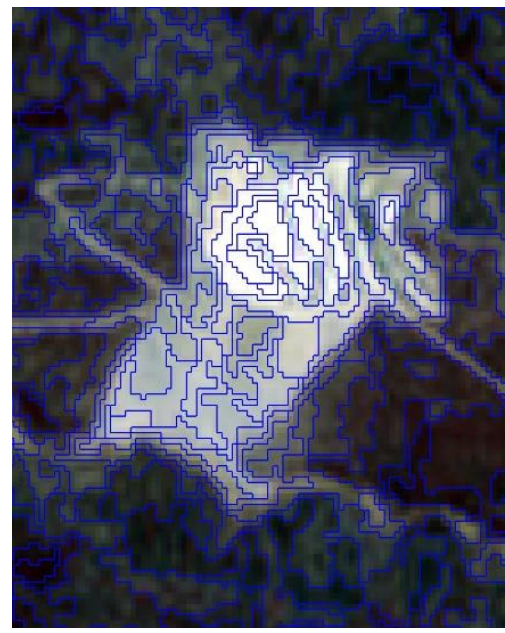

(a)

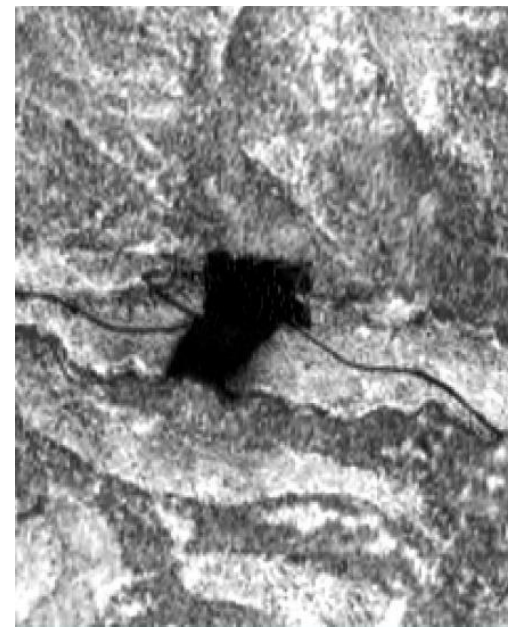

(b)

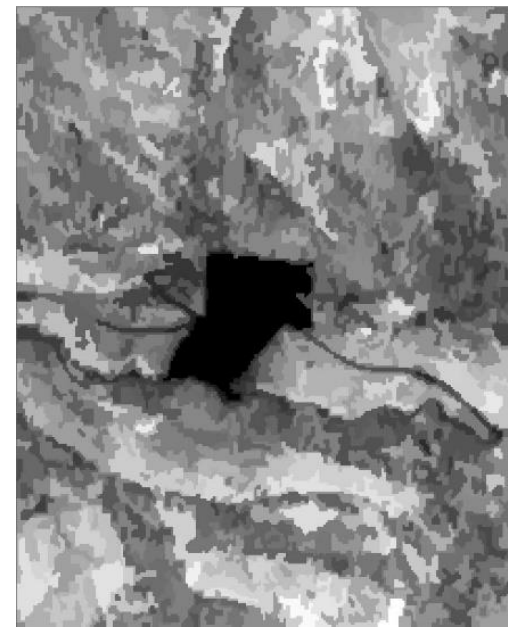

(c)

Şekil 3. (a) Maden sahası için görüntü nesneleri; (b) NDVI görüntü; (c) Görüntü nesneleri üzerinde NDVI.

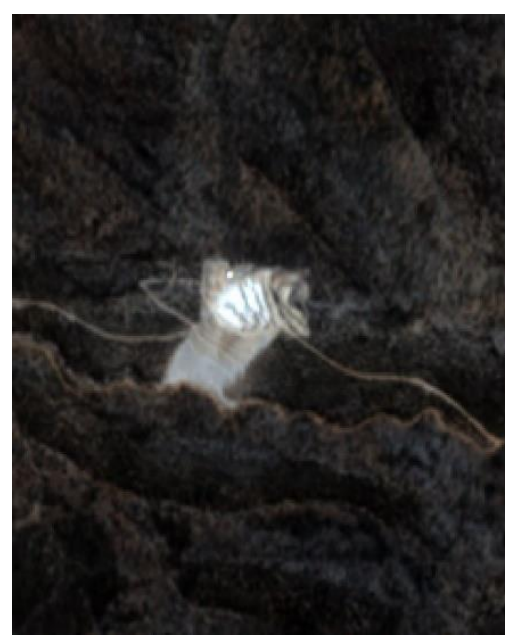

(a)

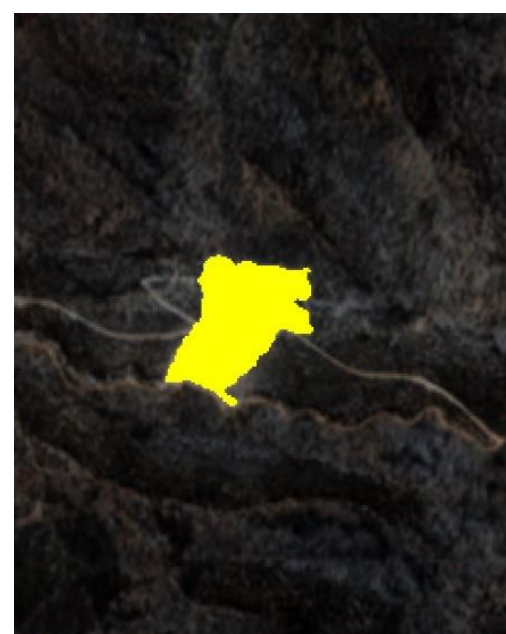

(b)

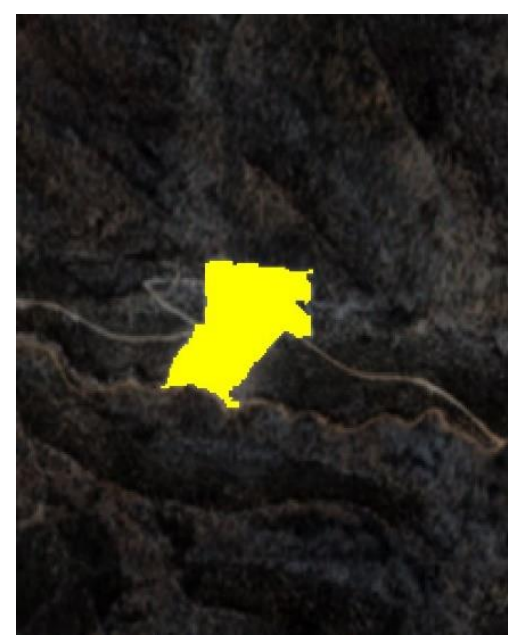

(c)

Şekil 4. (a) Ham görüntü; (b) Piksel tabanlı sınıflandırma; (c) Nesne tabanlı sınıflandırma. 


\section{YAKINLIK ANALIZI}

Açık maden sahası piksel tabanlı ve nesne tabanlı sınıflandırma teknikleri ile uydu görüntüleri üzerinden elde edilmiştir. Sınıflandırılmış görüntülerde maden alanına ait sınıf otomatik olarak vektörize edilerek dış sınır çıkarılmıştır. Vektör formatında çıkarılan maden sınırları ile çalışma alanına ait $4 \mathrm{~cm}$ yer örnekleme aralığına sahip ortofoto üzerinden sayısallaştırma ile elde edilen maden sınırı arasında yakınlık analizi gerçekleştirilmiştir. Şekil 5'te gösterildiği üzere yakınlık analizinde toplamda 3 adet maden sınırı vardır. Sınıflandırma ile elde edilen maden sınırlarında piksel etkisinden kaynaklanan keskinlikleri elimine etmek amacıyla Polynomial Approximation with Exponential Kernel (PAEK) işlemi uygulanmıştır. Yumuşatma olarak uygulanan bu yöntemde tolerans değeri görüntünün piksel boyutu olan $6 \mathrm{~m}$ olarak uygulanmıştır. Sayısallaştırma ile elde edilen referans sınır vektörü üzerinde PAEK uygulanmamıştır. PAEK uygulanan 2 adet maden sınır vektörü üzerinde her 6 m'de bir nokta üretilmiştir. Sayısallaştırma yapılan ortofotonun piksel boyutu zaten çok küçük olduğu için sınır boyunca nokta üretilmemiştir. Yakınlık analizi kapsamında çıkarılan ve sonrasında yumuşatılan vektörler üzerinde üretilen noktalar ile referans sınır arasındaki en kısa mesafe değerleri belirlenmiştir. En kısa mesafe değerleri yardımıyla ortalama, standart sapma, maksimum ve minimum değerler gibi istatistik sonuçlar hesaplanmıştır.

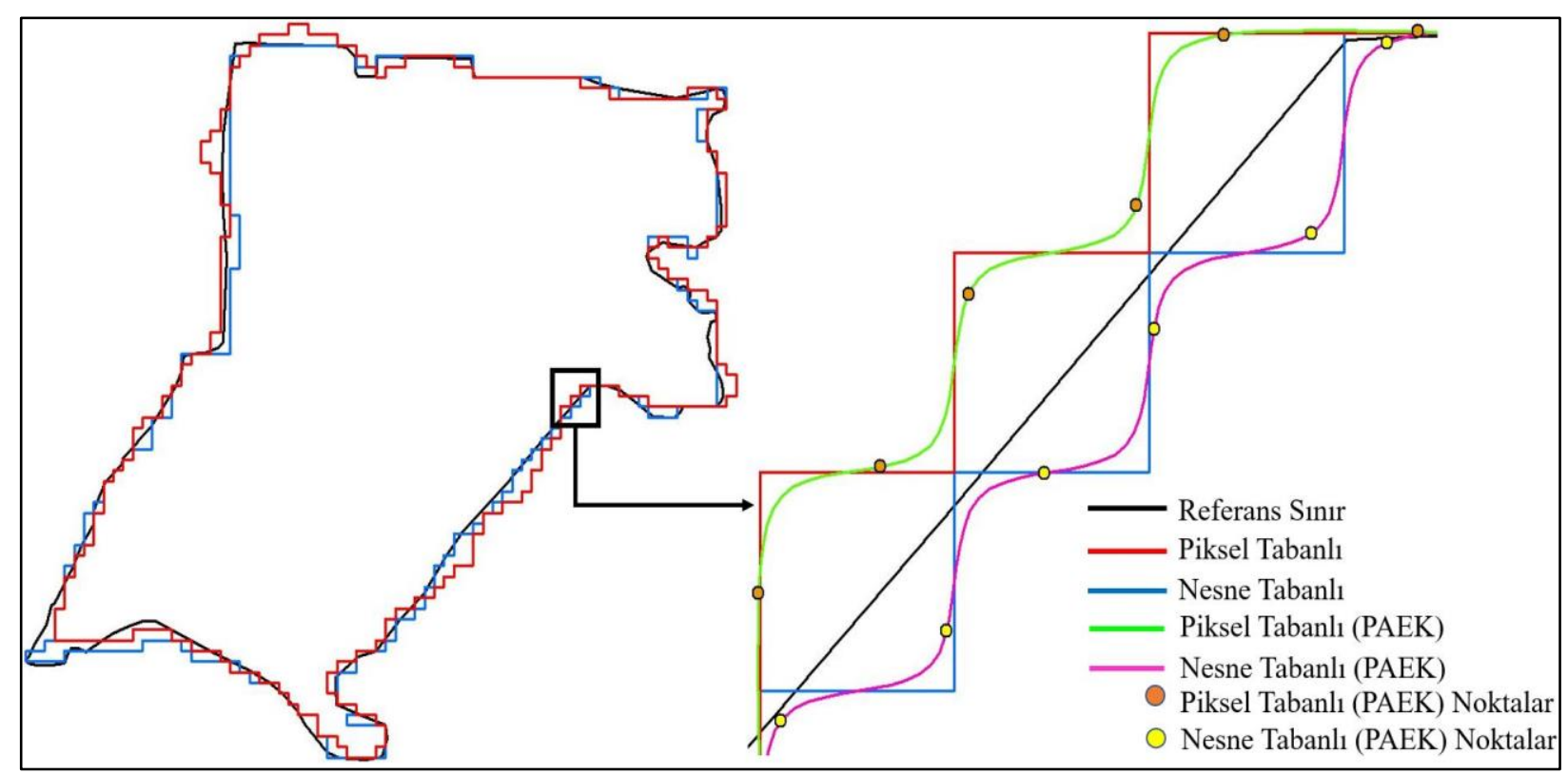

Şekil 5. Çıkarılan ve sayısallaştırılan maden sınırları, yumuşatılan vektörler ve üretilen noktalar.

\section{SONUÇLAR VE TARTIŞMA}

$\mathrm{Bu}$ çalışmada ormanlık alan içerisinde işletilmekte olan bir açık maden sahasının dış sınırları uydu görüntüsü üzerinden sınıflandırma teknikleri ile belirlenmiştir. Piksel tabanlı ve nesne tabanlı sınıflandırma teknikleri ile elde edilen sınırlar ortofoto üzerinden sayısallaştırma yardımıyla elde edilen referans sınır ile karşılaştırılmıştır. Çalışmanın başında da belirtildiği üzere 6 m'lik piksel boyutuna sahip görüntü ile $4 \mathrm{~cm}$ 'lik piksel boyutuna sahip görüntü doğruluk açısından birbirleriyle karşılaştırılmamaktadır. 6 m'lik piksel boyutuna sahip görüntüye uygulanan sınıflandırma teknikleri ile elde edilen sınırların referans olarak kabul edilen veriye ne kadar yaklaşabildiği incelenmiştir. Bu kapsamda sınıflandırma yöntemlerinden hangisinin daha iyi sonuç verdiği araştırılmıştır. EBB algoritmasının kullanıldığı piksel tabanlı sınıflandırma ve NDVI değerine dayalı olarak gerçekleştirilen kurala dayalı nesne tabanlı sınıflandırma için en yakın mesafe değerlerine göre Çizelge 1'de yer alan sonuçlar elde edilmiştir.

Çizelge 1. Yakınlık analizi sonuçları.

\begin{tabular}{|c|c|c|}
\hline İstatistik & Piksel Tabanlı (EBB) & Kurala Dayalı Nesne Tabanl \\
\hline Ortalama & 2.25 & 1.19 \\
Standart Sapma & 3.26 & 2.23 \\
Minimum & 0 & 0 \\
Maksimum & 15.4 & 15.18 \\
\hline
\end{tabular}

En yakın mesafe değerlerine bağlı olarak elde edilen sonuçlara göre ortalama uzaklık değerleri her iki teknikte de bir piksel boyutunun yarısından daha düşüktür. Minimum değerlerin 0 olması bazı bölgelerde sınırların çakışık olduğunu göstermektedir. Maksimum değerler incelendiğinde ise her iki teknikte de yaklaşık olarak 15 m’lik değerler 
mevcuttur. Şekil 6'da her iki teknik için minimum mesafe değerlerine ait grafikler incelendiğinde ise nesne tabanlı sınıflandırma için bir piksel boyutundan daha düşük değerlerin sayısının daha az olduğu görülmektedir.

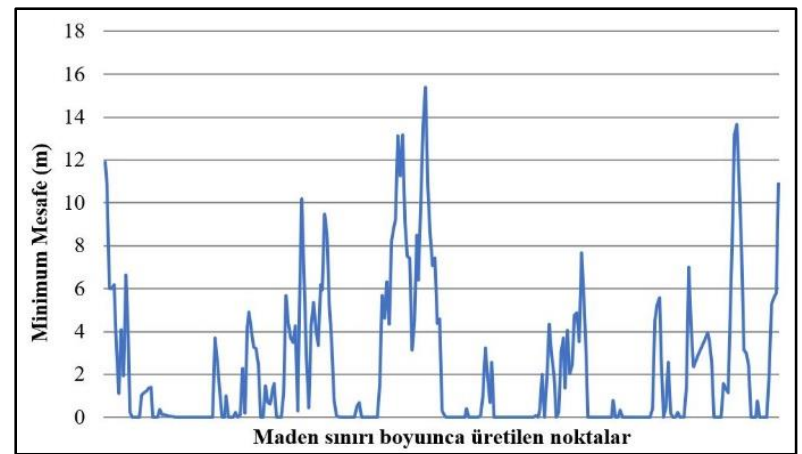

(a)

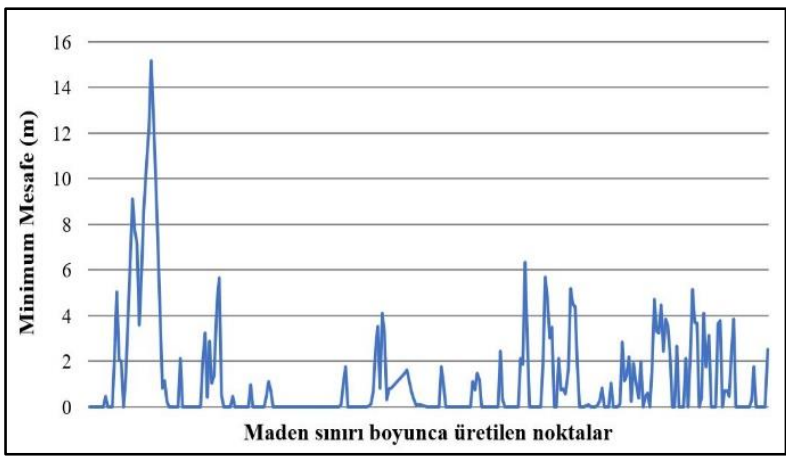

(b)

Şekil 6. (a) Piksel tabanlı sınıflandırma için ortalama mesafe grafiği (b) Nesne tabanlı sınıflandırma için ortalama mesafe grafiği.

İncekara vd. (2018) tarafından aynı çalışma alanında, nesne tabanlı sınıflandırma örnek alanlara bağlı olarak farklı parametrelerle gerçekleştirilmiştir. $\mathrm{Bu}$ çalışmada nesne tabanlı sınıflandırmanın kurala dayalı olarak gerçekleştirilmesi daha iyi sonuçlar elde edilmesini sağlamıştır. Ayrıca piksel tabanlı sınıflandırmada da önceki çalışmadan farklı örnek alanlar kullanılmıştır. Dolayısıyla örnek alanların sayısı ve dağılımındaki farklılıkların sonuçları etkilediği söylenebilir.

Bu çalışmada incelenen maden sahası yaklaşık olarak 9 hektar büyüklüğündedir. İHA ile elde edilen fotoğraflardan üretilen ortofoto üzerinden de sayısallaştırma yardımıyla maden sınırı kısa sürede elde edilebilmektedir. Bununla birlikte çok sayıda madenin zamansal kontrolünün toplu olarak yapılması durumunda daha geniş alanları kapsayan görüntü verileri gerekecektir. Bu durumda uydu görüntüleri daha iyi bir seçenek olarak değerlendirilmektedir. Ayrıca maden sahası ile birlikte çevresi de incelemeye dahil edilecekse, NIR bant istenilen sonuca ulaşmak için oldukça önemli bir yere sahiptir.

\section{TEŞEKKÜR}

Çalışmada kullanılan verilerin paylaşılmasındaki destekleri için İTÜ Uydu Haberleşme ve Uzaktan Algılama Merkezi ve ENK Harita Şirketine teşekkür ederiz.

\section{KAYNAKLAR}

Erener, A., 2011. Remote Sensing of Vegetation Health For Reclaimed Areas of Seyitömer Open Cast Coal Mine. International Journal of Coal Geology, 86: 20-26.

İncekara, A.H., Delen, A., Şeker, D.Z. ve Şanlı, F.B., 2018. Comparison of Pixel-Based and Object-Oriented Approach to Extract Boundary of Open Pit Mine in Forest Area. International Conference of Agriculture, Forest, Food and Veterinary Sciences and Technologies, İzmir, Türkiye, syf: 479-486.

Kavzoğlu, T. ve Yıldız, M., 2014. Parameter-Based Performance Analysis of Object-Based Image Analysis Using Aerial and Quickbird-2 Images. ISPRS Annals of the Photogrammetry, Remote Sensing and Spatial Information Sciences, İstanbul, Türkiye, II-7, syf: 31-37.

Paul, D., Banks, G., Ballard, C. ve Gillieson, D., 2006. Monitoring the Environmental Impact of Mining in Remote Locations through Remotely Sensed Data. Geocarto International, 21(1): 33-42.

URL-1., 2018. http://www.migem.gov.tr/Istatistik.aspx, [21.02.2018]. 